\title{
123. On the Nature of Factor L, a Specific Dietary Factor for Lactation.
}

\author{
By Waro Nakahara, Fumito InUkaI and Saburo Ugami. \\ Institute of Physical and Chemical Research, Tokyo. \\ (Comm. by U. Suzuki, M.I.A., Nov. 12, 1935.)
}

In a paper presented before the Imperial Academy in May, 1934, we showed that a new dietary factor, clearly distinguishable from vitamin B complex, is necessary for the process of lactation, and for this unidentified substance we proposed a tentative designation of "Factor L."1) The possible existence of such a.food factor as this has previously been suggested by other workers, but none of them offered any conclusive evidence to show that the hypothetical factor was different from vitamin $\mathrm{B}$ complex. The fact that another factor besides vitamin B complex, is necessary for lactation was more recently demonstrated also by Feaster and Nelson. ${ }^{2}$

After proving that the lactation promoting substance in liver extract is not adsorbed by acid earth and is therefore entirely different from vitamin $B$, we directed our efforts toward the purification of this substance. In experiments so far carried out we obtained a crude preparation of factor $\mathrm{L}$ by precipitation with phosphotungstic acid, which proved effective in daily doses of less than $50 \mathrm{mgr}$. per rat, indicating that by further purification this unidentified substance may be found to be active in a very minute amount.

The lack of space prevents our giving here the details of the chemical manipulations leading to the preparation of the crude phosphotungstic precipitate, but the essential steps employed may be represented as follows:-

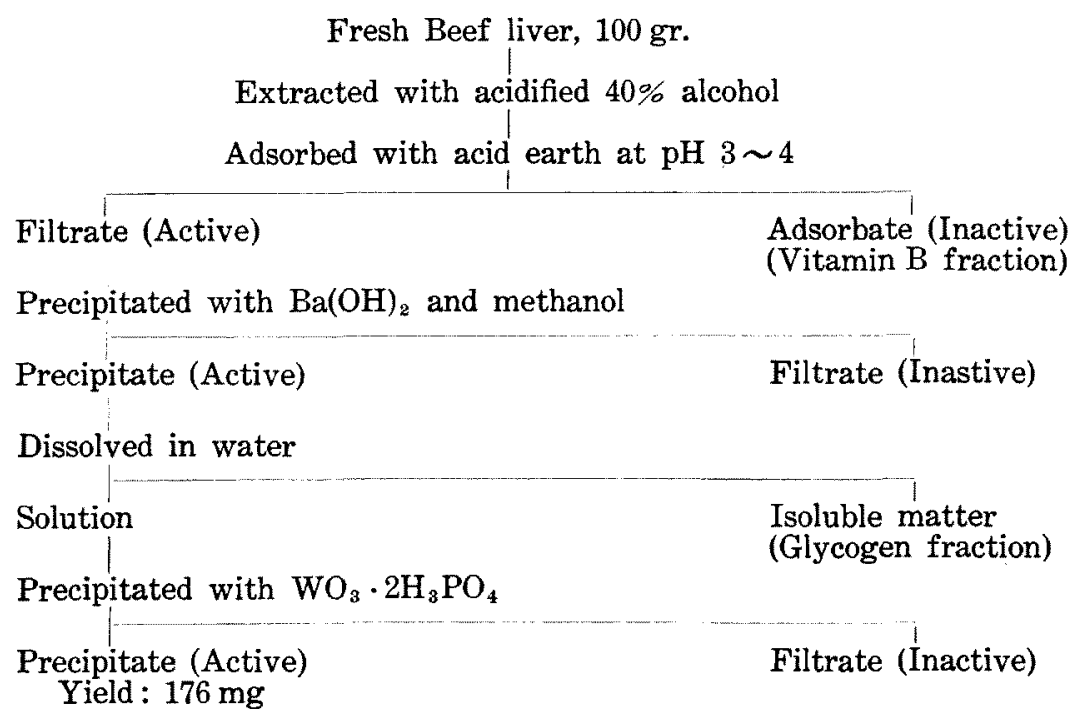

1) Nakahara, W., Inukai, F. and Kato, S.: Proc. 10 (1934), 268; Also Sci. Pap. Inst. Phys. Chem. Research, 24, 155 (1934).

2) Feaster, J. F. and Nelson, V. E.: Proc. Soc. Exper. Biol. Med., 32, 1456 (1935). 
No. 9.] On the Nature of Factor L, a Specific Dietary Factor for Lactation.

As may be clear from the above, the active substance in question is not adsorbed by acid earth but is precipitated by barium hydroxide, indicating that it has a character of acids. The fact that the substance is precipitated by phosphotungstic acid may be taken to point to its possibly containing nitrogen. It is, however, too early to speculate as to the exact chemical nature of factor $\mathrm{L}$.

The potency of each fraction mentioned above was tested according to the method we previously described, ${ }^{1)}$ with some modifications, which may be briefly stated as follows:-

A number of healthy virgin female rats $(130 \sim 150 \mathrm{gr}$. body weight) were maintained on a factor $\mathrm{L}$ deficient basal diet consisting of : polished rice powder $75 \mathrm{gr}$., fish protein $10 \mathrm{gr}$., butter $10 \mathrm{gr}$., McCollum's salt mixture $5 \mathrm{gr}$., and dried "Oriental" yeast $5 \mathrm{gr}$, for a preliminary period of two weeks. At the end of the first week, large healthy males were paired off with the females and allowed to cohabit until the end of the second week. Two weeks of feeding on this basal diet was sufficient to produce factor $\mathrm{L}$ deficiency in that pregnant females maintained on this diet for just two weeks preceding parturition practically always showed a total failure of lactation.

At this point the basal diet was supplemented with each of the fractions to be tested. The amount of the supplement to be added was so calculated as to represent the yield from $100 \mathrm{gr}$. of fresh liver per $100 \mathrm{gr}$. of basal diet. The females were allowed to go through gestation and parturition, and lactation, if capable, on the supplemented diet. Females not showing signs of pregnancy by the end of two weeks after removing the males were discarded, so that no female in the experiment received supplemented diet for less than two weeks or longer than three weeks-usually 16 to 19 days-before parturition.

The success or failure of lactation was determinable usually in two or three days after parturition, and females suckling the young were continued on the supplemented diet for three weeks after parturition, at the end of which the young were weaned.

The ratio of the number of young weaned against the number born was taken as the index of the efficiency of lactation.

Our data on lactation tests for all the fractions so far tested may conveniently be tabulated as follows:-

\begin{tabular}{l|ccc}
\hline & $\begin{array}{c}\text { No. of } \\
\text { females }\end{array}$ & $\begin{array}{c}\text { No. of young } \\
\text { born }\end{array}$ & $\begin{array}{c}\text { No. of young } \\
\text { weaned }\end{array}$ \\
\hline Whole extract* & 6 & 39 & $16(41.02 \%)$ \\
\hline Acid earth adsorbate* & 8 & 61 & $6(9.83 \%)$ \\
Non-adsorbable fraction* & 7 & 40 & $23(57.50 \%)$ \\
\hline Barium precipitate & 8 & 64 & $33(51.56 \%)$ \\
Barium filtrate & 9 & 72 & $11(15.27 \%)$ \\
\hline Phosphotungstic precipitate & 5 & 41 & $24(58.50 \%)$ \\
Phosphotungstic filtrate & 7 & 56 & $11(19.82 \%)$ \\
\hline Basal diet controls* & 14 & 98 & $1(1.02 \%)$ \\
\hline
\end{tabular}

* Data for these groups were taken from our previous papers.

1) Nakahara, W. and Inukai, F.: Sci. Pap. Inst. Phys. Chem. Research, 22, 301 (1933). 
In the above data we would call attention to the positive potency of the phosphotungstic precipitate. The estimated average amount of this fraction offered to a female was $51 \mathrm{mg}$. per day. Since the rat by no means completely consumed the total amount of their daily food given, the actual amount of the active fraction ingested by a rat may safely be regarded as being less than here indicated. Without doubt, a further purification of factor $\mathrm{L}$ will prove this substance to be active in a very much smaller quantity.

The total failure of lactation on the otherwise complete synthetic diet, and the ability of a minute amount of the identified substance (factor L) to prevent the failure, may class this substance under the category of accessory food factors, i.e., vitamins.

A detailed account of the present work will shortly appear in "Scientific Papers of the Institute of Physical and Chemical Research." 